\title{
DAS DISCÓRDIAS CIVIS ÀS VIAS EXTRAORDINÁRIAS, DO DESEJO DO POVO À IMPOSTURA DO PODER
}

\section{Dario de Negreiros ${ }^{1}$}

\begin{abstract}
Resumo: São bem conhecidos os elogios que faz Maquiavel à divisão social e ao conflito. Dirá, por exemplo, que "quem condena o tumulto entre os nobres e a plebe parece censurar as coisas que foram a causa primeira da liberdade de Roma”. Mas que os tumultos sejam a causa da liberdade, há muitas formas de compreendê-lo. Se é Maquiavel um louvador do conflito, seria-o apenas, para muitos, desde que ele se expresse por meio do ordenamento legal e das vias institucionais. Trataremos, aqui, de outro Maquiavel: autor atento às formas como a opressão se traveste de democracia, ao modo como a República, mesmo sem promover o rompimento da ordem legal, pode interverter-se em autoritarismo - e que, para romper as amarras deste legalismo autoritário, convoca-nos à transgressão e à conspiração. Eis o Maquiavel de Claude Lefort.
\end{abstract}

Palavras-chave: Maquiavel. Claude Lefort. Le travail de l'oeuvre Machiavel. Revolução ciompi. Vias extraordinárias. Discórdias civis.

Quando a plebe entrou no Palácio, levava a insígnia do gonfaloneiro de justiça certo Michele di Lando, cardador de lã. Este, descalço e com pouca roupa, subiu ao salão seguido por toda a turba e, chegando à sala de audiências dos Senhores, parou e, voltando-se para a multidão, perguntou: "Estais vendo: este Palácio é vosso, e esta cidade está nas vossas mãos. Que achais melhor fazer agora?” A isso todos responderam que o queriam como gonfaloneiro e senhor, para governar a cidade como bem lhe parecesse.

Maquiavel, Istorie Fiorentine, Livro III, Cap. 16

Quando o historiador, na perspectiva realista que lhe é própria, acusa Maquiavel ou Marx de se afastar dos fatos e de trair a verdade histórica, ele se engana. Ele nos faz lembrar o parente do romancista que fica indignado com as transformações impostas aos acontecimentos, às paisagens, aos personagens dos quais o relato tira sua substância. [...] por mais que seja escabroso sustentar a comparação até o fim, e considerar o Bórgia maquiaveliano ou o Bonaparte

1 Graduado em Jornalismo, Psicologia e Filosofia, é mestrando do Departamento de Filosofia da USP, sob orientação da Prof. Marilena Chauí. E-mail: darionegreiros@gmail.com 
marxista como nós consideraríamos Odette de Crécy ou o barão de Charlus, não é menos verdadeiro que o vício do realismo perverte a leitura da obra de pensamento tanto quanto a da obra de arte, que existe uma afinidade entre os modos de expressão da filosofia e da literatura, que os personagens de Maquiavel e os do romancista têm igualmente, em graus diferentes, uma função simbólica. O estranho é que a gente admita de boa vontade, atualmente, que a obra de arte é obra de pensamento, mas não a recíproca.

Claude Lefort, Le travail de l'oeuvre Machiavel

Michele de Lando: homem da plebe, cardador de lã, ciompo. Visto que lhe fizera nascer paupérrimo, no seio da mais ignóbil posição social que poderia à época ocupar um florentino, não se exagera ao dizer que nunca lhe havia sido grata a fortuna. Mas se seus dotes dela não obteve, Michele os recebera, antes, da natureza (cf. Istorie, III.16) ${ }^{2}$. E quando, comportando-se com a feminilidade que lhe é própria, acenou-lhe fortuitamente a fortuna, este plebeu a agarrou pelos cabelos, domou-a, tratou-a com a ousadia e a impetuosidade característica dos jovens, mostrando que em ânimo, prudência e bondade superava, naquele tempo, qualquer outro cidadão (cf. Istorie III.17). Ocorre que o tempo, bem sabemos, tudo caça diante de si. E a roda da fortuna, que com tanta virtù Michele fizera conduzir-lhe do baixo ao alto, tampouco oferece outro caminho para quem está no topo senão aquele que leva indivíduos e sociedades, homens e Repúblicas, às suas inexoráveis e lamentáveis desgraças.

Que personagem é este que, com a habilidade dos grandes romancistas, Maquiavel constrói em sua História de Florença? E - para que sustentemos até o fim a "escabrosa" comparação sugerida por Lefort (TdOM, p. 69) ${ }^{3}$ - se o modo como Marcel Proust descreve o caminhar do barão de Charlus, em nada devendo à astúcia dos grandes pensadores, antecipa, desvela e sintetiza os tormentos internos que a sua afetada indiferença aristocrata mal consegue disfarçar, que diríamos, então, desta cinematografia maquiaveliana na qual um pobretão semi-nu, carregando a insígnia da Justiça, adentra o Palácio recémconquistado a ferro e fogo pela plebe e, perguntando à multidão "que achais melhor fazer agora?", recebe como resposta que deveria "governar como bem lhe parecesse" (Istorie, III.16)?

É a esta cena, imagem maior da revolução ciompi, que dedicamos o

2 Para nos referirmos à "História de Florença”, utilizaremos sempre a designação "Istorie", sendo as citações seguidas do número do Livro, em numerais romanos, do número do Capítulo, em algarismos arábicos, e do número da página (São Paulo: Martins Fontes, 2007).

3 Convencionamos o acrônimo "TdOM" para nos referirmos a Le travail de l'oeuvre Machiavel (Paris: Gallimard, 1972). 
presente texto. A ela nos debruçando, e sempre nela nos apoiando, trataremos da mais importante questão que surge da leitura do Proêmio, do III.1, do IV.1 e do VII.1, a saber: como entender o estatuto da divisão civil nas Istorie? Questão que nos levará, por certo, a outras que lhe são correlatas.

Ainda no Proêmio, algumas passagens já começam a ouriçar os leitores acostumados aos Discorsi ${ }^{4}$. Florença, relata, dividiu-se internamente mais do que qualquer outra cidade: não contente com a desunião entre os nobres e a plebe, nela, nobres disputaram entre si, nobres e povo discordaram e, finalmente, dividiram-se povo e plebe. Divisões das quais resultaram mortes, exílios, destruições de famílias, "como nunca ocorreu em nenhuma cidade de que se tenha memória" (Istorie, Proêmio, p.8). Suposta mudança de tom do autor em relação às discórdias civis, que para muitos restaria clara na frase que abre o III.1: "as graves e naturais inimizades que há entre os homens do povo e os nobres [...] são razão de todos os males da cidade" (Istorie, III.1, p.157) ${ }^{5}$.

Que teria havido, perguntam-se sobressaltados os comentadores, com aquele Maquiavel que enfaticamente afirmava que "quem condena os tumultos entre os nobres e a plebe parece censurar as coisas que foram a causa primeira da liberdade de Roma" (Discorsi, I.4, p.21) e que, havendo em toda república dois humores distintos, "todas as leis que se fazem em favor da liberdade nascem da desunião deles" (idem, p.22)? Onde estaria aquele autor segundo o qual os bons exemplos de virtù nascem da boa educação, que nasce das boas leis que, finalmente, nascem "dos tumultos que muitos condenam sem ponderar" (idem)?

Devagar com o andor prossigamos, antes que inadvertidamente nos unamos ao coro dos comentadores assustados.

Lembremos que, de início, no primeiro parágrafo do Proêmio, Maquiavel alertava: os excelentes historiadores de Florença que o precederam, ao privilegiarem o relato das guerras e disputas externas, não deram às discórdias civis e às inimizades internas a importância que lhes seria devida, de modo que em suas descrições "os leitores não podem encontrar utilidade nem prazer

4 Para nos referirmos aos "Discursos sobre a primeira década de Tito Lívio", utilizaremos sempre a designação "Discorsi", sendo as citações seguidas do número do Livro, em numerais romanos, do número do Capítulo, em algarismos arábicos, e do número da página (São Paulo: Martins Fontes, 2007). 
algum" (Istorie, Proêmio, p.7). Utilidade, ressalta, que não seria pouca, visto que "se alguma lição há que seria útil aos cidadãos que governam as repúblicas, é aquela que demonstra os motivos dos ódios e das divisões da cidade" (idem, p.8). Tal lacuna historiográfica, justifica Maquiavel, levou-o a uma mudança de rota, abandonando os planos de iniciar sua obra no ano de 1434 - ano da volta de Cosimo de' Medici do exílio, marca do início da senhoria dos Medici, que lhe haviam encomendado a obra, e cujo domínio se estenderia até $1532^{6}$-, para narrar a história de Florença desde o princípio.

Ora, de imediato, e para além de qualquer dúvida possível, resta absolutamente clara a importância e centralidade das divisões civis na história maquiaveliana. Deslocando o foco narrativo das disputas externas às internas, e reconstruindo o escopo temporal de modo a relatar não a história de uma família que instaurou um principado no interior de uma república, mas a história de uma Cidade, Maquiavel faz com que a população florentina assuma, de saída, o protagonismo da história.

Este caráter nuclear conferido aos conflitos internos constitui prova inequívoca de que, se de fato houver alguma mudança de julgamento por parte do autor em relação ao caráter benéfico das divisões civis, podemos afirmar que, ainda assim, elas nada perderam em termos de interesse e importância.

Mas, antes de discutirmos o estatuto das divisões civis nas Istorie, lembremos, ainda, que não há nada mais maquiaveliano do que o discurso sinuoso, o raciocínio tortuoso e manifestamente contraditório, que se apropria dos argumentos do seu adversário para, fazendo-os seus, melhor dissecá-los, expondo em vísceras a falácia escondida no interior das opiniões consensuais e falsamente a-problemáticas. Debatedor astuto, que procede não como quem instala o inimigo em campo oposto e impermeável ao diálogo, mas como quem, para derrubá-lo, caminha ao seu lado e, no momento oportuno, corta a grama que está sob seus pés.

Como bem lembra Lefort:

Maquiavel se apoia novamente sobre a opinião estabelecida, antes de subverter os princípios a partir dos quais ela se reclama. [...] Sob a promessa de um relato, Maquiavel se prepara para lançar uma ideia cujo alcance é universal; ao se apossar de um enunciado teórico largamente aceito, ele se prepara para deslizar um exemplo que, em vez de fornecer uma ilustração, desnatura a sua significação. (TdOM, p.472)

6 Domínio quase centenário, interrompido apenas por um breve intervalo de dezoito anos, entre 1494 e 1512 . 
É neste momento que devemos, seguindo o conselho lefortiano, mergulhar novamente na empiria, avaliando os exemplos lançados pelo autor florentino logo após as polêmicas afirmações do III.1. Voltemos, pois, ao nosso espetáculo histórico-teatral.

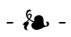

Impossível analisarmos tal cena sem retomarmos o discurso deste homem, dos mais audazes e experientes ciompi. Proferido no calor dos acontecimentos, incitando a turba ao tumulto, acendendo mais "os já inflamados ânimos para o mal” (Istorie, III.13), este ciompo anônimo dirá:

Não deve assustar-vos a antiguidade do sangue que eles nos jogam ao rosto; porque todos os homens tiveram o mesmo princípio e são, por isso, igualmente antigos, e foram feitos de um mesmo modo pela natureza. Fiquemos todos nus, e vereis que somos semelhantes e se nos vestirmos com as vestes deles, e eles com as nossas, vereis que, sem dúvida, nós pareceremos nobres, e eles, não nobres. (Istorie, III.13, p.185)

Tomados por si só, o destaque e a força retórica com a qual o autor constrói este belíssimo discurso já nos parecem indicar algo sobre o seu posicionamento diante dele. Mas é possível, de fato, que Maquiavel esteja ao lado destes vândalos, destes incendiários, desta turba de arruaceiros que tão logo escutava “à casa de Fulano!", pronta estava para queimá-la, sem maiores cerimônias (cf. Istorie, III.14)? Não seria Maquiavel, como querem muitos de seus comentadores, o fiel escudeiro da República, o defensor audaz das vias ordinárias, um louvador do conflito - dúvidas não há -, mas desde que este se expresse e se escoe exclusivamente por meio do ordenamento legal e das vias institucionais?

De fato, para comentadores como Viroli, as "repúblicas livres devem estar aptas a moderar as paixões e desejos dos cidadãos, de modo a que não transgridam os limites das leis civis" (Viroli, 1998. apud Cardoso, 2015), restando claro que, em Maquiavel, "a base do vivere civile seria o 'princípio da legalidade” (Cardoso, 2015). Nessa perspectiva, seriam louváveis, para o secretário florentino, apenas os conflitos "que respeitam, enfim, de maneira inflexível, as exigências de legalidade" (Cardoso, 2015).

Mas se assim o fosse, ora, por qual motivo Maquiavel se referiria de modo tão elogioso à revolta dos ciompi? Como poderíamos compreender, por 
exemplo, o fato de que o discurso com o qual a plebe é incitada ao tumulto reúne alguns dos principais leitmotivs do pensamento maquiaveliano?? "Com efeito, o ciompo se utiliza", como bem observa Del Lucchese (2001, p. 90), em comentário posteriormente retomado por José Luiz Ames (2014):

do conceito de necessidade: "mesmo que nada mais nos ensinasse, a necessidade nos ensinaria" (Istorie, III.13); ou ainda da noção de ocasião oferecida pela fortuna: "é preciso usar de força quando é dada a ocasião. E ocasião melhor não poderia ser oferecida pela fortuna..." (idem); ou, finalmente, da ideia de que a fraude e a força são inseparáveis da política: "mas se notardes o modo como os homens procedem, vereis que todos aqueles que conseguem grandes riquezas e grande poder os conseguiram com a fraude ou com a força" (idem).

Difícil a um leitor atento, portanto, não enxergar como laudatórios os relatos maquiavelianos à revolução ciompi, impressão que só se reforçará, nos capítulos subsequentes, com os rasgados elogios do autor a Michele de Lando ${ }^{8}$. A leitura segundo a qual Maquiavel seria radicalmente comprometido com a chamada rule of law, portanto, claramente não dá conta de interpretar seus próprios escritos. Mas em que contexto se insere tal sorte de elogio às vias extraordinárias e àqueles que as empregam?

Lembremos que, poucos capítulos antes, "muitos cidadãos, movidos pelo amor à pátria” (Istorie, III.5), já haviam deixado claro o caráter corrompido da república florentina de então, denunciando o caráter particularista dos interesses daqueles que à época disputavam o poder:

Porque o prêmio da vitória que desejam não é a glória de terem libertado a cidade, mas a satisfação de terem vencido os outros e usurpado o principado dela; e, chegados a tal ponto, nada há que seja tão injusto, cruel ou ganancioso que não ousem fazer. Por isso, as ordenações e as leis não são criadas para a utilidade pública, mas para a utilidade própria [...]. (Istorie, III.5)

Que fazer, pois, quando a República, mesmo sem promover o rompimento da ordem legal, interverte-se em autoritarismo, disfarçando sorrateiramente interesses privados sob a capa de bens públicos? Como agir quando as instituições republicanas se petrificam, quando a opressão de poucos contra

7 "Nas palavras do ciompo são retomados muitos dos temas expressos por Maquiavel em suas obras" de modo que, "ao descrever aquela posição, está disposto a emprestar muitos de seus argumentos" (Del Lucchese, 2001, p. 90. apud Ames, 2014).

8 Conforme trecho ao qual já fizemos referência, Maquiavel dirá: "Vencida a empresa, acalmaram-se os tumultos, apenas graças à virtù do gonfaloneiro. Este, em ânimo, prudência e bondade, superou naquele tempo qualquer outro cidadão" (Istorie, III.17, p.196). 
muitos se confunde, se imiscui e procura se legitimar na letra supostamente universal de um ordenamento jurídico pretensamente democrático? Que fazer, enfim, quando a tirania se traveste de democracia, quando a República se corrompe e, do republicanismo, nada guarda senão o nome?

Reconstruamos, aqui, alguns pontos da leitura lefortiana de Maquiavel - a única que, aos nossos olhos, é capaz de responder esta questão.

Tomemos, de início, este célebre postulado maquiaveliano:

[...] Porque em toda cidade se encontram estes dois humores diversos: e nasce, disto, que o povo deseja não ser nem comandado nem oprimido pelos grandes e os grandes desejam comandar e oprimir o povo. (Principe, III, p.35)

Como sabemos, existem, para Maquiavel, três modos de resolução possíveis desta discordância de humores, deste conflito interno ou, como dirá Lefort, desta luta de classes:

- $1^{\circ}$ modo: "se ela engendra um poder que se eleva acima da Sociedade e a subordina inteiramente à sua autoridade: temos o principado" (TdOM, p.381);

- $\quad 2^{\circ}$ modo: "ou a sociedade se regula de tal maneira que ninguém está assujeitado a ninguém (ao menos de direito): temos a liberdade (ou, se quisermos, a República, a democracia)" (TdOM, p.381);

- $\quad$ ou, $3^{\circ}$ modo: "ela é impotente para se refundar no seio de uma ordem estável, e temos a licença" (TdOM, p.381).

Eis que neste segundo modo de resolução - o da organização republicana surge, para alguns comentadores, uma espécie de happy end do conto de fadas maquiaveliano: as instituições republicanas seriam capazes de prover ao conflito dos desejos, ou à luta de classes, uma saída institucional, um escoamento legal, ordeiro, fundado na universalidade da lei e, sobretudo, no desejo do povo, solução por meio da qual, ninguém estando assujeitado a ninguém, ter-se-ia a democracia e a liberdade de todos. Eis como alguns dos críticos do "mito da boa sociedade" reeditam, à sua maneira, a mesma crença que denunciam.

É certo, contudo, que Maquiavel está longe de ser tão otimista e ingênuo para dar, assim, a questão por resolvida. Afinal, o florentino estava mais do que acostumado a enxergar a opressão existente no interior da ordem republicana. Pois os interesses facciosos, avessos ao bem comum, ou seja, "a pura discórdia, 
tumulto no qual se chocam os interesses particulares", lembra-nos Lefort, "se acomoda muito bem, como acontece em Florença, com a aparência da ordem isto é, com o equilíbrio adquirido das forças sociais" (TdOM, p. 477).

Muito longe de construir uma oposição rígida entre principado e república, tirania e liberdade, o autor florentino se esforça, antes, para embaralhar sistematicamente estes conceitos, operando o que Lefort chamará de uma "aproximação entre tirania e república" (TdOM, p. 500). Maquiavel mostrará, com efeito:

que o regime republicano não é de uma outra essência que o regime de dominação aberta e que, em consequência, uma tirania pode se adaptar às suas principais exigências. (TdOM, p. 496)

Não se trata, aqui, de "apagar a oposição entre tirania e regime livre" (TdOM, p. 495). Seria um grave erro, lembra-nos Lefort, supor que, para Maquiavel, "uma boa tirania" pode ser melhor do que uma República ruim. Trata-se, portanto, não de apagar esta importante oposição, mas de "modificarlhe os termos, de maneira que ela se torne incerta” (TdOM, p. 495). E, principalmente, modificar-lhe de tal modo que nós, leitores, nos tornemos sensiveis às estratégias por meio das quais os Grandes sempre procuram, de modo mais ou menos bem sucedido, se utilizar das instituições republicanas para saciar seu desejo de opressão.

Assim, graças a essa modificação dos termos da oposição, a esse embaralhamento das fronteiras entre principado e república, entre governo tirânico e democrático, Maquiavel nos permite enxergar como, muitas vezes, "no seio de um governo livre, os Grandes oprimiam o povo" (TdOM, p. 496). É este o "elogio cruel" de Maquiavel sobre o funcionamento da República, funcionamento que a leva à sua progressiva corrupção: "a liberdade, da qual fazemos tanto caso, recobre para uns a oportunidade de comandar e, para outros, a segurança" (TdOM, p. 496). Longe da liberdade, nada mais cabe ao povo na República corrompida senão a patética e lamentável demanda por um mínimo de segurança.

E não pensemos, tampouco, que república sã e república corrompida constituam, para Maquiavel, uma oposição estanque: ao contrário, se a eterna refundação é imprescindível, ela o é justamente porque a corrupção da república, o enrijecimento de suas instituições, o afastamento do legal em relação ao legítimo são tendências permanentes, vetores sempre presentes e atuantes, contra os quais se nos impõe a tarefa de lutar. De fato, Maquiavel nos 
mostra que:

apesar das aparências, o regime republicano tende a se petrificar seguindo o mesmo processo que a monarquia; que ele incita o governante a se identificar com o poder, a autoridade e a lei, ao ponto de cegá-lo sobre sua tarefa; que o Sujeito político deve se afirmar na crítica desta identificação e na liberdade da transgressão. (TdOM, p. 621)

Para romper as amarras do autoritarismo legal, ou do legalismo autoritário, Maquiavel nos convoca, assegura Lefort, à transgressão. A verdadeira ação política em uma República corrompida é invariavelmente extra-institucional e, ainda que legítima, ilegal, pois voltada contra uma opressão que é, por sua vez, ainda que ilegítima, legal, pois encarnada, concretizada, sustentada e reproduzida pelo aparato institucional e jurídico da República.

Já não nos parecem mais tão estranhos, após os esclarecimentos lefortianos, o modo elogioso com o qual Maquiavel descreve o uso das vias extraordinárias adotadas pelos ciompi - especialmente se mantivermos em mente, ressaltemos, o caráter corrompido da república de então, denunciado anteriormente por aqueles "cidadãos, movidos pelo amor à pátria" (Istorie, III.5). Tampouco nos parece, a essa altura, existir ainda alguma dúvida sobre o quão equivocados estão aqueles que acreditam encontrar, nas Istorie, uma mudança de tom de Maquiavel em relação à sua valorização das divisões civis. Como bem resume Sérgio Cardoso:

Não obstante o caráter tumultuário e frequentemente violento da expressão dos 'desejos dos povos livres" - que Maquiavel assegura serem 'raras vezes perniciosos à liberdade (Discursos, cap.4) - [...] em Florença, a "ínfima plebe" os 'Ciompi” - leva a cidade à criação de novas corporações (alargando o universo da cidadania), à anulação de dívidas, anistias e outras leis. (Cardoso, 2015)

Tratemos, por fim, de um último tema, ao qual esta riquíssima cena que analisamos também pode lançar luz. Notemos como o emprego das vias extraordinárias - justificado por este conceito, tão bem descrito por Lefort, de legitimidade transbordante, de excesso do legítimo em relação ao legal, desta particular forma de Lei que deve sempre estar em eterno transpasso das fronteiras de sua determinação empírica atual - é radicalmente indissociável do 
aparecimento de um Outro: o Sujeito político. "É a mesma coisa”, dirá Lefort:

reconhecer que o principio não é determinável do ponto de vista empírico, ou, segundo nossa terminologia, que a lei transcende todas as instituições nas quais ela toma figura, e descobrir o lugar do Sujeito político. (TdOM, p. 601)

Mas, perguntemos: onde poderá apoiar sua ação aquele que deve agir contra a ordem estabelecida? Vejamos, enfim, o que faz o Sujeito político de nossa cena, o virtuoso Michele de Lando.

'Estais vendo: este Palácio é vosso, e esta cidade está nas vossas mãos. Que achais melhor fazer agora?' A isso todos responderam que o queriam como gonfaloneiro e senhor, para governar a cidade como bem lhe parecesse. (Istorie, III.16)

Talvez não haja, em toda a obra de Maquiavel, nenhuma outra cena que deixe mais claros, de um só golpe, dois dos princípios mais fundamentais de sua teoria política: de um lado, o caráter radicalmente negativo do desejo do povo e, de outro, a cisão, o fosso intransponível entre o Povo e o Poder, o Social e o Político, vazio no qual procura ininterruptamente se sustentar, qual equilibrista em invisível corda bamba, o Sujeito político.

Logo após tomar o Palácio, Michele de Lando deixa claro o lugar em que deve apoiar sua ação. "Que achais melhor fazer agora?", pergunta à plebe, consciente de que é este desejo o único princípio disponível para lhe servir como direcionamento de suas ações. Mas o que é o desejo do Povo?? Desejo de não ser oprimido, polo negativo do desejo dos Grandes, negação de um apetite de opressão. Eis que encontramos, no seio do político, a figura da negatividade: $o$ lugar do poder, para existir, não terá outra escolha a não ser a de se apoiar em um desejo essencialmente negativo.

Estabelece-se, assim, uma relação de dupla dependência: o Povo, incapaz de ocupar por si o poder, depende de Michele. Este, apoiado que está no Povo, não poderá governar legitimamente com o simples apelo à força, devendo aparecer como aquele que defende o desejo popular e que a ele se identifica: sua imagem deve se afirmar como reflexo de um desejo negativo.

9 Como bem diz Sérgio Cardoso, "não é tarefa fácil balizar este caminho de surgimento das leis quando se concede a uma 'negatividade pura' o lugar do fundamento da ordem política" (Cardoso, 2015). De fato, excederíamos em muito o escopo do presente texto se quiséssemos, aqui, esgotar a temática da negatividade do desejo do povo. Limitar-nos-emos, então, apenas àquilo que, desta discussão, ilumina a análise de nossa cena e, inversamente, àquilo que, desta cena, ilumina nossa discussão. 
Mas quem é Michele, no instante em que toma o Palácio, estandarte da Justiça em mãos? Quê vê a plebe, que à sua frente se aglomera, quando lhe dirige o olhar? Veria nele um dos seus? Ou veria, antes, alguém que passou ao outro lado - ou seja, que, de representante do povo, dos oprimidos, tornou-se representante dos Grandes, dos opressores?

A resposta, atentemo-nos, não é dita: ela aparece na função simbólica da imagem. "Fiquemos todos nus, e vereis que somos semelhantes [...]" (Istorie, III.13, p.185).

Ora, não é por acaso que apenas três capítulos após o discurso deste audaz e experiente representante dos ciompi (cf. Istorie, III.13, p.184), no qual todos são convocados a se despirem das vestes que os desigualam, Maquiavel faz adentrar ao Palácio um ciompo "descalço e com pouca roupa" (Istorie, III.16). Sem vestes nobres, sem os trapos plebeus, este homem, nu, não é mais representante nem dos Grandes, nem do Povo. Nem plebe, nem nobre: é para além desta oposição, pois, que se instala o Poder.

$\mathrm{Da}$ divisão originária do social, do conflito insolúvel entre as classes, $o$ Poder surge como aquisição de uma unidade imaginária e formulação de uma solução impossível, que só se realizam ao preço da instituição de uma nova cisão:

o poder só é poder se se destacar do social para resolver sua divisão, engendrando, porém, outra, entre o social e o político. (CHAUÍ, 1974, p.54)

Tal é, enfim, o paradoxo do Sujeito Político: por ser pura negatividade, não pode o desejo popular ocupar diretamente o lugar do poder - muito embora lhe sirva de fundamento - vendo-se obrigado a erigir-se em um Outro, um terceiro, que nasce de uma dinâmica social para dela imediatamente se destacar. Desejo, pois, que no exato segundo em que ascende ao Poder condena seu representante à eterna impostura de sua representação, não lhe oferecendo nada além do capcioso imperativo: "governe como bem lhe parecer".

Carente de conteúdo determinado, negatividade essencial, o desejo do Povo é um desejo sem rosto que encontra numa máscara sua única face possível. Solução de um problema insolúvel, superação de uma divisão insuperável, eis a posição de Michele de Lando: posição imaginária, que oculta uma divisão, e posição simbólica, que institui a cisão da sociedade entre os campos do social e do político. Estranha verdade efetiva das coisas, que melhor se revela quanto mais se a teatraliza. Estranha nudez, que não pode afirmar o real senão ao preço de denegá-lo. 


\section{REFERÊNCIAS}

AMES, J.L. (2014). Transformações do significado de conflito na "História de Florença" de Maquiavel. Kriterion, Belo Horizonte, n 129, Jun./2014, p. 265286.

CARDOSO, S. (2015). Em direção ao núcleo da 'obra Maquiavel': sobre a divisão civil e suas interpretações. Disponível em: www.claudelefort.com.

CHAUÍ, M. (1974). Resenha do livro de Claude Lefort "Le Travail de l'œuvre, Machiavel". Departamento de Ciências Sociais - Cadeira de Ciência Política. São Paulo: Universidade de São Paulo (USP).

DEL LUCCHESE, F. "'Disputare' e 'combattere'. Modi del conflitto nel pensiero politico di Niccolò Machiavelli'. Filosofia Politica, Ano15, Nr. 1, pp. 71-98, abr. 2001.

LEFORT, C. Le Travail de l'œuvre, Machiavel. Paris: Gallimard, 1972.

MAQUIAVEL. Discursos sobre a primeira década de Tito Lívio. São Paulo: Martins Fontes, 2007.

MAQUIAVEL. História de Florença. São Paulo: Martins Fontes, 2007. MAQUIAVEL. O Príncipe. São Paulo: Hedra, 2011. 


\section{DE LAS DISCÓRDIAS CIVILES A LAS VIAS EXTRAORDINÁRIAS, DEL DESEO DEL PUEBLO A LA IMPOSTURA DEL PODER}

Resumen: Son bien conocidos los elogios que hace Maquiavelo a la división social y al conflicto. Dirá, por ejemplo, que "quien condena el tumulto entre los nobles y la plebe parece censurar las cosas que fueron la causa primera de la libertad de Roma". Pero que los tumultos sean la causa de la libertad, hay muchas formas de comprenderlo. Si es Maquiavelo un elogiador del conflicto, lo sería sólo, para muchos, desde que se exprese por medio del ordenamiento legal y de las vías institucionales. Trataremos aquí de otro Maquiavelo: autor atento a las formas como la opresión se disfraza de democracia, al modo como la República, aun sin promover el rompimiento del orden legal, puede transformarse en autoritarismo - y que, para romper las amarras de este legalismo autoritario, nos convoca a la transgresión ya la conspiración. Este es el Maquiavelo de Claude Lefort.

Palabras-clave: Maquiavelo. Claude Lefort. Le travail de l'oeuvre Machiavel. Revolución ciompi. Vías extraordinarias. Discordias civiles.

\section{FROM CIVIL CONFLICT TO EXTRAORDINARY WAYS, FROM THE PEOPLE'S WILL TO THE IMPOSING OF POWER}

Summary: Machiavelli's praise of social division and conflict is well known. He says, for example, that "anyone who condemns the tumult between the nobles and the plebe seems to censor the things which were the first cause of the liberty of Rome." But that tumults are the cause of freedom, there are many ways of understanding it. If Machiavelli is praising the conflict, would it be only as long as it expresses itself through a legal order and institutional ways? No: we will deal here with another Machiavelli. An author attentive to the ways in which oppression disguises itself as a democracy, to the way in which the Republic, even without promoting the breaking of the legal order, can turn into authoritarianism. And, in order to break the bonds of this authoritarian legalism, he summons us to transgression and conspiracy: this is Machiavelli by Claude Lefort.

Keywords: Machiavelli. Claude Lefort. Le travail de l'oeuvre Machiavel. Revolution ciompi. Extraordinary ways. Civil conflict. 
Das discórdias civis às vias extraordinárias... 